\title{
The Clostridium small RNome that responds to stress: the paradigm and importance of toxic metabolite stress in C. acetobutylicum
}

Keerthi P Venkataramanan ${ }^{1,2}$, Shawn W Jones ${ }^{1,2}$, Kevin P McCormick ${ }^{2,3}$, Sridhara G Kunjeti ${ }^{2,4}$, Matthew T Ralston ${ }^{2,5}$, Blake C Meyers ${ }^{2,4}$ and Eleftherios T Papoutsakis ${ }^{1,2^{*}}$

\begin{abstract}
Background: Small non-coding RNAs (sRNA) are emerging as major components of the cell's regulatory network, several possessing their own regulons. A few sRNAs have been reported as being involved in general or toxic-metabolite stress, mostly in Gram ${ }^{-}$prokaryotes, but hardly any in $\mathrm{Gram}^{+}$prokaryotes. Significantly, the role of sRNAs in the stress response remains poorly understood at the genome-scale level. It was previously shown that toxic-metabolite stress is one of the most comprehensive and encompassing stress responses in the cell, engaging both the general stress (or heat-shock protein, HSP) response as well as specialized metabolic programs.

Results: Using RNA deep sequencing (RNA-seq) we examined the sRNome of $C$. acetobutylicum in response to the native but toxic metabolites, butanol and butyrate. $7.5 \%$ of the RNA-seq reads mapped to genome outside annotated ORFs, thus demonstrating the richness and importance of the small RNome. We used comparative expression analysis of 113 sRNAs we had previously computationally predicted, and of annotated mRNAs to set metrics for reliably identifying sRNAs from RNA-seq data, thus discovering 46 additional sRNAs. Under metabolite stress, these 159 sRNAs displayed distinct expression patterns, a select number of which was verified by Northern analysis. We identified stress-related expression of sRNAs affecting transcriptional (6S, S-box \& solB) and translational (tmRNA \& SRP-RNA) processes, and 65 likely targets of the RNA chaperone Hfa.

Conclusions: Our results support an important role for sRNAs for understanding the complexity of the regulatory network that underlies the stress response in Clostridium organisms, whether related to normophysiology, pathogenesis or biotechnological applications.
\end{abstract}

\section{Background}

Small non-coding regulatory-RNAs (sRNAs), discovered on the genome of all bacteria so far examined, have been established as an integral component of the regulatory system of the cell [1-3]. Unlike their counterparts in eukaryotes, which are about 20 nucleotides long, sRNAs in bacteria span a wider size range between 50 to 500 nts [4]. Regulation of gene expression at post-transcriptional level by sRNAs has been established in both Gram', such as Vibrio fischeri [5], Pseudomonas aeruginosa [6], and Escherichia coli [1,7], and $\mathrm{Gram}^{+}$bacteria,

\footnotetext{
*Correspondence: epaps@udel.edu

'Department of Chemical and Biomolecular Engineering, University of Delaware, Newark, DE, USA

${ }^{2}$ Delaware Biotechnology Institute, University of Delaware, Newark, DE, USA

Full list of author information is available at the end of the article
}

such as Bacillus subtilis [8], Listeria monocytogenes [9] and Streptococcus pyogenes [10]. Identification of sRNAs in bacteria has been carried out experimentally using whole genome microarrays, intergenomic tiling arrays, shotgun cloning and, recently, RNA deep sequencing (RNA-seq) [7,11-14]. In silico prediction of sRNAs has been carried out using comparative genomic analyses by employing algorithms such as SIPHT [15], QRNA [16], ISI [17], and sRNAscanner [18]. Experimental detection of sRNAs that are expressed only under specific culture conditions may not be successful at other conditions, while computational methods relying on sequence conservation may not identify species-specific sRNAs. Hence, a combination of the two approaches should be logically preferable.

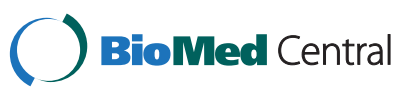


A number of sRNAs have been identified to play an important role in the response to stress in Escherichia coli, such as in oxidative stress (OxyS) [19], cold shock (SraF, SraG and SraJ) [1], iron depletion $(R y h B)$ [20-22] and sugar stress (SgrS) [23]. The best and most celebrated case so far uncovered is the regulation of the major stress sigma factor, RpoS, in E. coli. RpoS orchestrates the cellular response to a variety of stresses and the transition to the stationary phase, and is regulated at the posttranscriptional level by several sRNAs. DsrA, RprA and ArcZ are positive regulators the RpoS expression, while OxyS is a negative regulator [24-26]. Yet, little is known regarding a role of sRNAs in the stress response of $\mathrm{Gram}^{+}$ prokaryotes, and nothing about the role of sRNAs in the response to chemical stress. Here we are focusing on the stress-responsive small RNome of Clostridium acetobutylicum, a model organism for the Clostridium genus and more broadly the anaerobic endospore formers [27]. Clostridium organisms are $\mathrm{Gram}^{+}$, endospore-forming firmicutes capable of fermenting a very broad set of substrates and are of great importance in human and animal pathogenesis and health, cellulose degradation, non-photosynthetic $\mathrm{CO}_{2}$ fixation, bioremediation and biotechnology, such as for the production of solvents and other chemicals in the context of biofuel and biorefinery applications $[27,28]$.

The response to chemical stress, whether from autologous metabolites or allogeneic toxic chemicals (such as from carboxylic acids, high $\mathrm{H}^{+}$concentrations (low $\mathrm{pH}$ ), antibiotics, and solvents like ethanol and butanol), plays a major role in cell physiology. Chemical stress affects cell survival, metabolism, sporulation and pathogenesis in physiological milieus, such as the gut microbiome [29], and pathogenesis [19,30-32], and the natural environment. Chemical stress is a major and well recognized problem in modern bioprocessing due to toxic substrates and desirable or undesirable toxic metabolites [33]. Chemical stress in Clostridium organisms engages the general stress response, better known as the heatshock protein (HSP) response, as well as more specialized responses. The HSP response involves strong upregulation of all major HSP proteins, including those of the GroESL and DnaKJ systems. Specialized responses include the acid resistance systems under acid stress [34-36], and changes in metabolic and biosynthetic programs in response to both acid and solvent stress [35,37-39]. Thus, chemical stress is one of the broadest stress responses known in this and other prokaryotes, and as such, understanding the stress-related small RNome under chemical stress is of broad and general interest.

C. acetobutylicum carries out the biphasic ABE (acetonebutanol-ethanol) fermentation, which consists of an acidogenic exponential phase resulting in the production of butyrate and acetate, followed by the solventogenic stationary phase characterized by the production of acetone, butanol and ethanol, and driven by the reassimilation of the acids. Using a SIPHT-based comparative genomics method, we recently predicted the existence of 113 sRNAs in $C$. acetobutylicum, among which 31 were validated by either Q-RT-PCR or Northern analysis [40]. The goal of this study is to identify sRNAs, at the genome scale, that respond to butanol and/or butyrate stress and possibly start assigning mechanistic roles for these sRNAs. sRNAs that modulate the stress response can be engaged to engineer strains tolerant to these toxic metabolites, as we and others have recently reported for both C. acetobutylicum [34] and Escherichia coli [36,41].

\section{Results and discussion}

\section{A large set of temporal RNA-seq data is essential for discovery}

Using RNA-seq, we aimed to identify sRNAs (previously predicted [40] and novel) that are differentially expressed under butanol and butyrate stress. To do so, we aimed to collect a large set of temporal data, which, based on our experience are more likely to lead to robust discovery outcomes $[35,38,39,42]$. Cultures of $C$. acetobutylicum were grown in batch mode in 4-L bioreactors up to the midexponential phase of growth (O.D 1.0), at which point the cultures were stressed with three different concentrations of butanol and butyric acid, respectively, in 3 biological-replicate experiments each. For butanol stress experiments, the cultures were stressed with $30 \mathrm{mM}$ (low), $60 \mathrm{mM}$ (medium) and $90 \mathrm{mM}$ (high), while for butyric-acid stress, $30 \mathrm{mM}$ (low), $40 \mathrm{mM}$ (medium) and $50 \mathrm{mM}$ (high) butyrate concentrations were used. These levels of metabolite stress were chosen based on prior studies $[35,38,39]$ and preliminary experiments to achieve the desirable low, medium or strong metabolic response to the applied stress. Cultures were sampled at 15, 30, 60 and 75 min post stress for RNA isolation and sequencing. These sampling times, which are of the order of the doubling time of these cells, were meant to capture largely the direct and immediate impact of these stresses on gene expression and the small RNome. Following RNA isolation, mRNA and sRNA enrichment, cDNA generation, adapter ligations and indexing, libraries were deep sequenced using Illumina's second generation HiSeq 2000 with a read length of $50 \mathrm{bp}$.

High sequencing depth was observed for all 84 sequenced libraries from samples representing 7 distinct culture conditions with 4 time points and 3 biological replicates each. On average, for each sequenced library, $18,162,979$ total reads were obtained, which are indicative of a high sequencing depth (Additional file 1). From these, for each sequenced library, 9,537,317 reads were mapped into the genome with 884,618 distinct reads after discarding unreliable reads. $46.5 \%$ of the reads 
mapped to annotated genes, while $2 \%$ of the reads were mapped to the 113 sRNA we have previously predicted [40]. The balance reads were mapped to structural RNA components (47\%) and interoperonic (IOR; genomic DNA between operons [43]) and intergenic regions (IGR; DNA between annotated ORFs) (5.5\%). These data suggest that the stress transcriptome is very rich in transcripts beyond those coded by ORFs and rRNA components.

\section{Read count distribution and metrics for robust identification of sRNAs}

Aiming to identify novel sRNAs and also assess which sRNAs are transcribed as part of the stress transcriptome, we desired to set metrics that would allow us to call experimental reads from the RNA-seq data as factually identifying sRNAs. To do so, we used two criteria for identifying novel sRNAs on IORs. First, we selected IORs with RNA-seq expression exceeding a minimal value of read counts based on the previously annotated sRNAs as well as annotated ORFs (protein coding mRNAs) (Figure 1). The majority (ca. 75\%) of annotated mRNAs had a minimum of 50 read counts (Figure 1A). The 113 sRNAs we had previously predicted [40] were divided into two categories: 31 previously validated sRNAs and the balance of 82 sRNAs (Figure 1B and 1C). As expected, read counts for sRNAs were lower than read counts for mRNAs. The majority of the previously validated 31 sRNAs had read counts over 50 (Figure 1B). The remaining 82 sRNAs had a read count distribution more skewed towards lower read counts (Figure 1C). Based on these data, we chose 50 as the read count that would most robustly identify IORs containing new sRNAs. No effort was made in this study to identify sRNAs coded on the opposite strand of annotated ORFs. Using this "minimum 50 " read count criterion, 729 IORs were identified as possibly containing novel sRNAs.

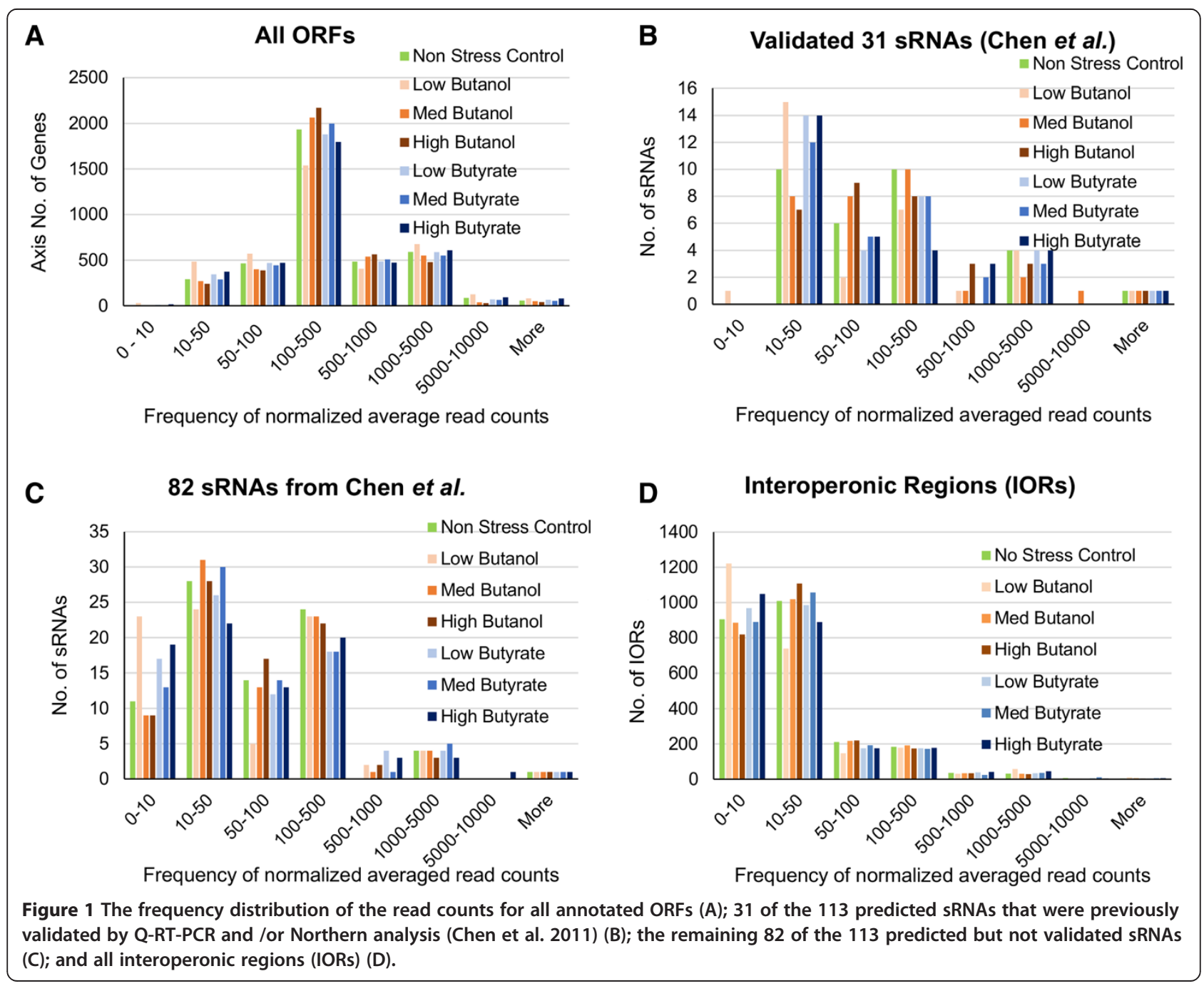


As the second selection criterion, SIPHT-based computational analysis for predicting sRNAs in the genome of C. acetobutylicum was performed, and 79 sRNA candidates, in addition to the previously identified 113 sRNAs, were found to be present within these 729 IORs. These were chosen for further analysis. To minimize false positives, we eliminated from the candidate list IORs having read counts predominantly from the 5 ' and 3' untranslated regions (UTRs) of the neighboring ORFs (genes), provided the neighboring ORFs also had a significant read counts $(\geq 50)$. This elimination process was executed with the aid of a custom web viewer built to visually analyze the RNA-seq data (Figure 2). Following the screening for false positives, we successfully identified 46 novel sRNAs (Additional file 1).

\section{What sRNAs are expressed and differentially expressed under metabolite stress}

We examined the expression profiles of the 159 (113 previously identified and the newly identified 46) sRNAs aiming to identify which are expressed and differentially expressed under the various metabolite-stress conditions. 114 of the 159 sRNAs had a minimum expression of 50 read counts in $20 \%$ of the sequenced libraries, while 70 of the 159 sRNAs had read counts over 50 read counts for $90 \%$ of the sequenced libraries representing a very broad set of culture conditions. Expression of genes and sRNAs are specific to culture conditions and not all of them are expressed at all culture conditions. Thus, expression of over $60 \%$ of the predicted sRNAs under all culture conditions in this study provides strong support for an important role of sRNAs in orchestrating the cellular response to metabolite stress.

Using pair-wise (for each time point) analysis of the 159 sRNAs for each level of metabolite stress against the unstressed control, we identified sRNAs that were differentially expressed with a p-value (DEseq analysis, Bioconductor package) $\leq 0.05$. Under both butanol and butyrate stress, the number of differentially expressed sRNAs were found to be dependent on the level of stress (Figure 3A). For example, we identified 32 of the 159 sRNAs as being downregulated under low butanol stress (Figure 3A). In contrast, under medium and higher levels of butanol stress, the number of downregulated sRNAs was significantly lower. Under butyrate stress, the largest number of downregulated sRNAs was found at low levels of stress, as well. This larger number of differentially downregulated genes under lower stress levels was also observed in the mRNA expression analysis (Additional file 2: Table S1).

Butyrate stress gave rise to more (45) differentially upregulated sRNAs than butanol stress (33), while butanol

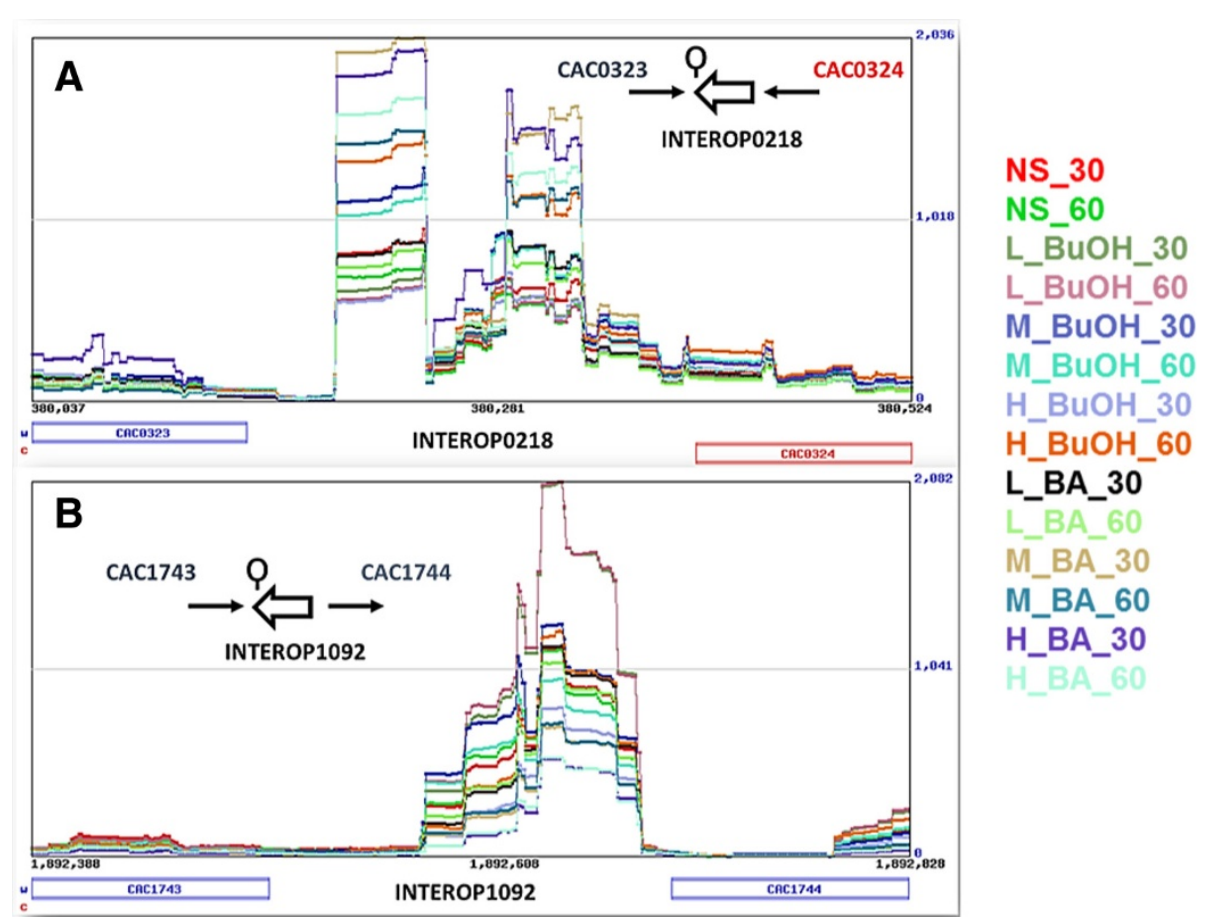

Figure 2 Custom web viewer to analyze the RNA-seq data and predict novel sRNAs in C. acetobutylicum. RNA-seq data screenshots of two predicted candidate sRNAs and their orientation (thick arrows), neighboring genes $(\rightarrow / \leftarrow)$ and Rho-independent terminators $(Q)$ are shown. The sRNA in (A) INTEROP0218 (sCAC381; a predicted Hfq target: see text) was validated by Northern analysis (Figure 5), while (B) sCAC1893 (INTEROP1092) was found to contain $\sigma^{G}$ element (Additional File 1). BuOH- butanol, BA- butyrate, NS- no stress, 30 \& 60 min post stress. 


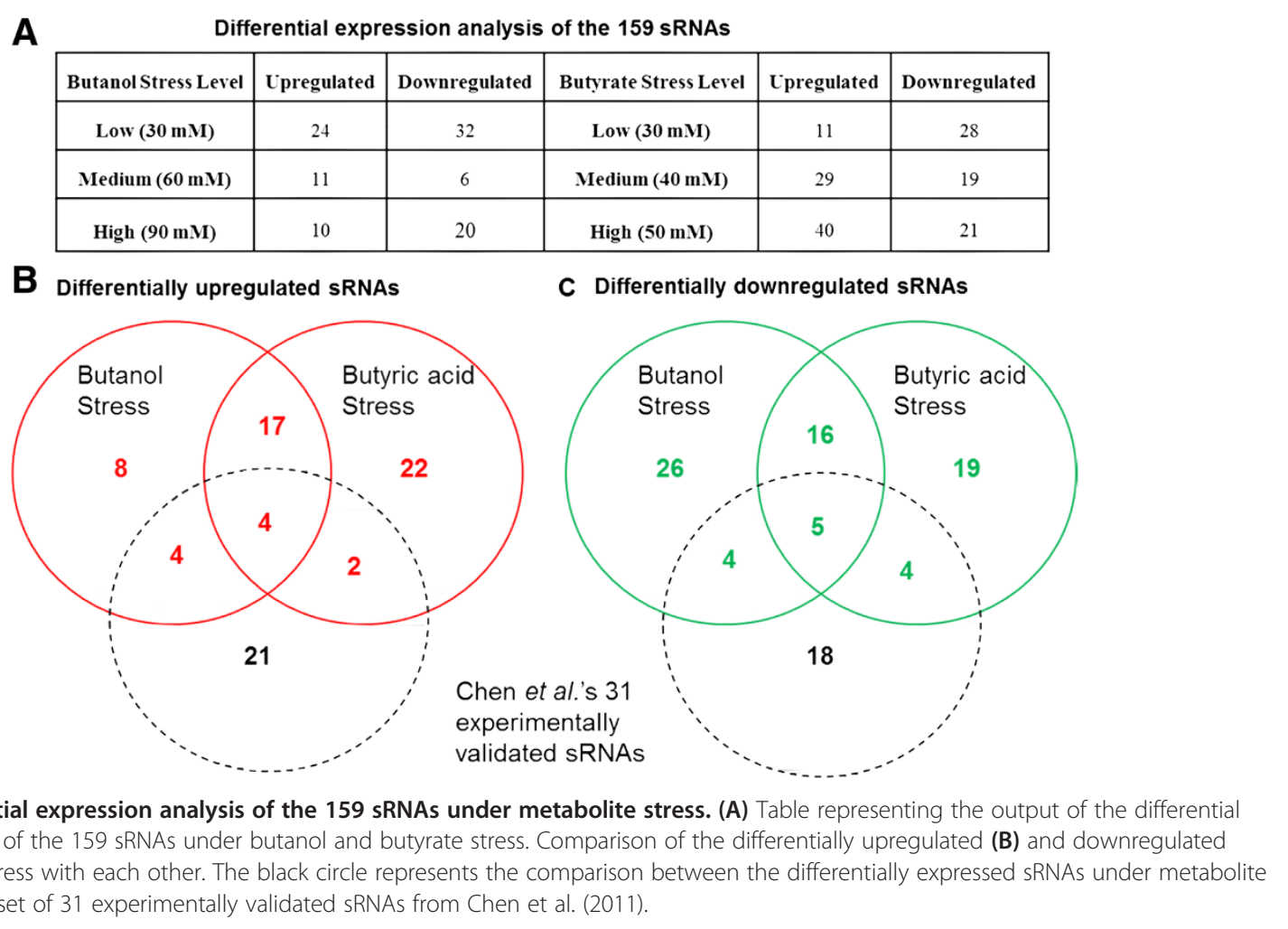

stress had more differentially downregulated sRNAs (51) compared to butyrate (44). 42 sRNAs were differentially expressed under both metabolite stresses: 21 were upregulated and 21 were downregulated under both stresses (Figure 3B \& 3C). Although the two metabolite stresses result in differential expression of specific sets of sRNAs that are stress and dose dependent, we found a considerable conservation of expression patterns for the two stressors among these sRNAs, thus suggesting a possible role of these sRNAs in the general stress response.

\section{Northern analysis of select stress-related sRNAs}

Among the differentially expressed sRNAs under metabolite stress described above, 31 have been previously validated by Northern and/or Q-RT-PCR analysis [40]. Here, we used Northern analysis (using single-stranded DNA probes to identify the strand specificity of the sRNA [34]) to examine the patterns of expression of a select number of differentially-expressed sRNAs. Selection was based on potential relevance to metabolite stress response (see below), but also on the ability to design probes, which requires that sRNAs have high GC content or GC rich regions. $\operatorname{tmRNA}$ (sCAC834), when analyzed by Northern blot, resulted in a single prominent band of ca. 300 nts. Northern blots of $6 S$ (sCAC1377) and S-box (SAM, sCAC1132) (Figure 4) revealed multiple bands indicating possible post-transcriptional processing by enzymes such as RNaseP, as has been reported [44].

The sRNA predicted on INTEROP0218 (sCAC381 174 nt - predicted length), INTEROP0009 (sCAC22 - 48 nt - predicted length), INTEROP1858 (sCAC3276 - 129 nt - predicted length) and INTEROP1958 (sCAC3463 $156 \mathrm{nt}$ - predicted length) were successfully validated as being metabolite-stress responsive, with experimentallyestimated sizes (Figure 5) consistent with computational predicted lengths. Northern analysis of sCAC381 revealed two bands ( 300 bp and $\sim 174 \mathrm{bp}$ ), indicating possible RNA processing or two transcriptional start sites (TSS for the larger transcript may be located upstream of the regular TSS, but this needs to verified using either strand specific sequencing or $5^{\prime} \mathrm{RACE}$ ).

\section{Patterns of expression: hierarchical clustering of sRNA expression under metabolite stress}

Expression patterns under metabolite stress of the 159 sRNAs were compared against the non-stressed control cultures (pair-wise \& point-by-point) and analyzed using hierarchical clustering. Both butyrate and butanol stress data displayed distinct clusters. Butyrate stress data resulted in four clusters. The 1st, "red", cluster (Figure 6B) represents sRNAs that were expressed consistently higher compared to the control. The $2^{\text {nd }}$ "green" cluster (Figure 6C) consists of weakly downregulated 


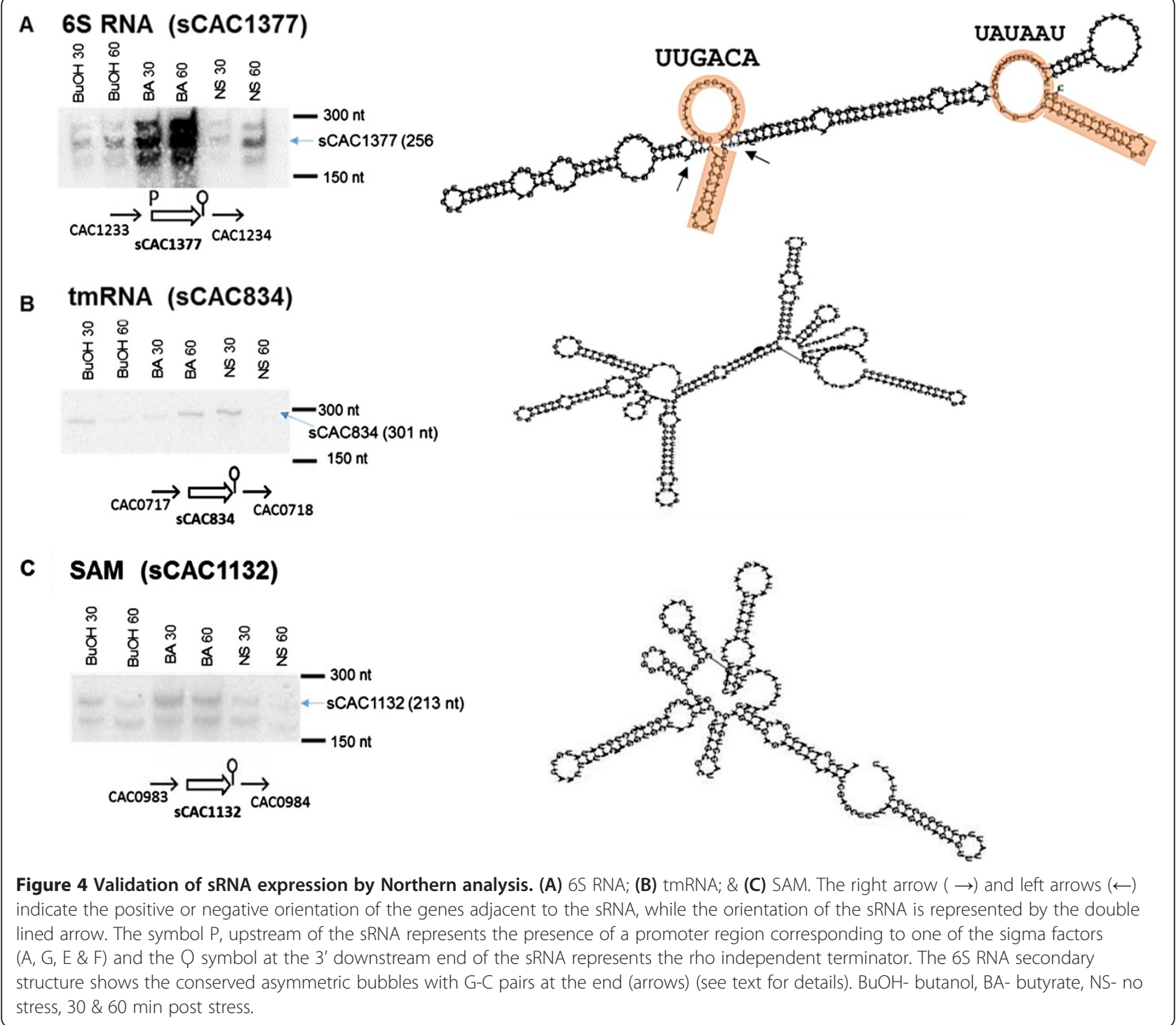

sRNAs. The $3^{\text {rd }}$ cluster (Figure 6D) contained sRNAs that were downregulated with a small delay post-stress. The 4th cluster (Figure 6E) contains sRNAs showing a stronger (> 4.0 fold) downregulation at all three levels of butyrate stress. The blue plots display the level of relative expression (intensity ranking) among all sRNAs [45], and combined with the differential expression heat maps, provide a more accurate assessment of temporal patterns in differential expression and strength of expression. The sRNAs in the $1^{\text {st }}, 2^{\text {nd }}$ and $4^{\text {th }}$ cluster show overall higher expression levels compared to the sRNAs of the $3^{\text {rd }}$ cluster.

sRNA expression under butanol stress also resulted in distinct, but more complex clusters. The $1^{\text {st }}$ cluster represented mostly upregulated sRNAs (Figure $7 \mathrm{~B}$ ). The $3^{\text {rd }}$ small cluster contained consistently downregulated sRNAs (Figure 7D). The remaining three clusters displayed a more complex pattern. The $2^{\text {nd }}$ cluster (Figure 7C) contained upregulated sRNAs only at low levels but not at medium or high levels of butanol stress. The $4^{\text {th }}$ and $5^{\text {th }}$ clusters (Figure 7E \& $7 \mathrm{~F}$ ) consisted of sRNAs that were downregulated at low levels of butanol stress, but not consistently so for medium or high levels of stress. The newly identified sRNAs, sCAC3400 (INTEROP1928), sCAC3507 (INTEROP1985) and sCAC2920 (INTEROP1658) were found to be upregulated under both stress conditions (Figures 6B \& 7B), and these sRNAs had relatively stronger upregulation under butyrate stress than under butanol stress. Typically most target mRNAs of the trans sRNAs are located at a distant and different location on the genome. For example, the sRNAs ArcZ, DsrA, RprA and OxyS target the stress specific sigma factor RpoS in E. coli despite being located at different loci on the genome 

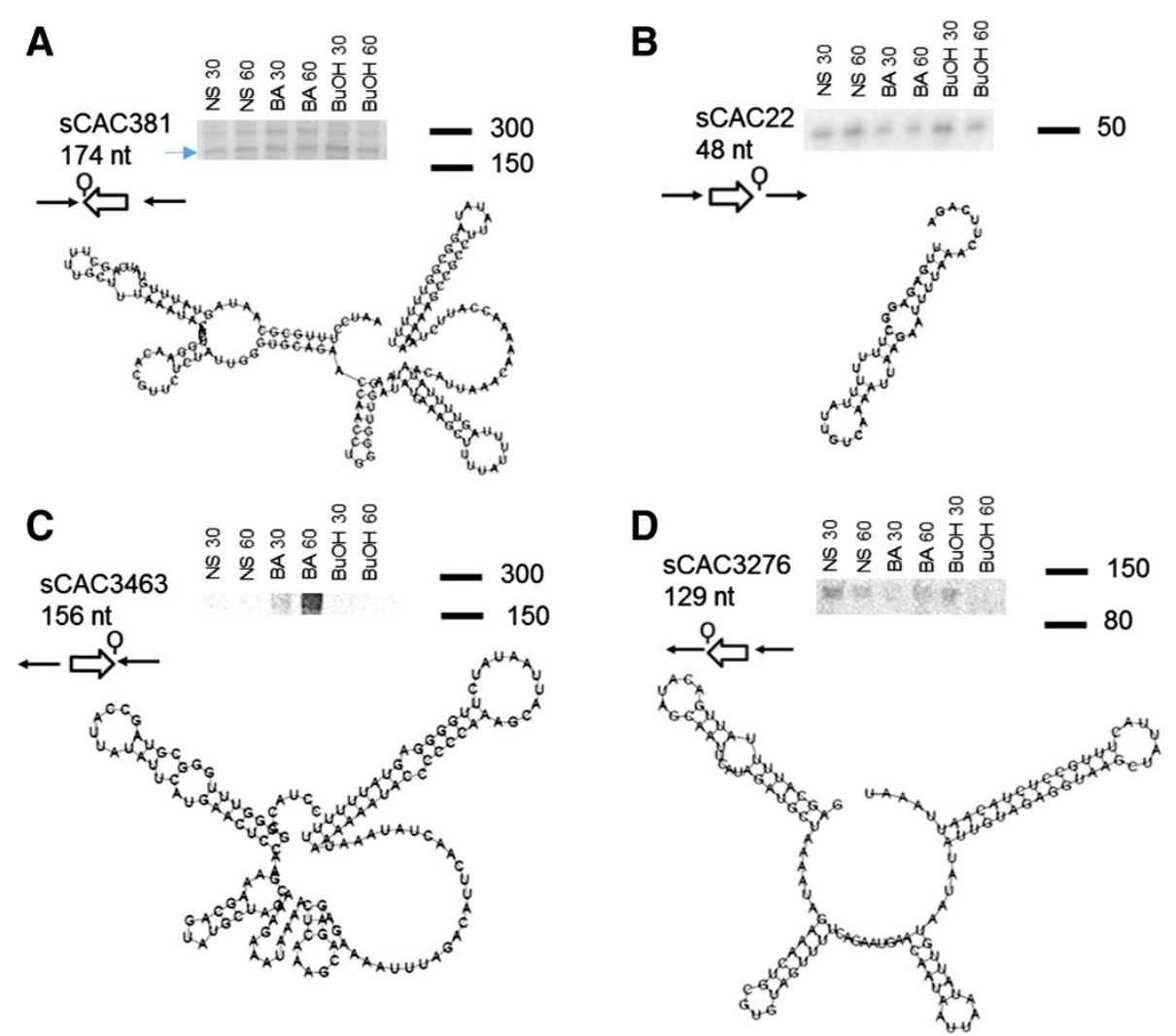

Figure 5 Northern analysis of select, newly identified sRNAs and their predicted secondary structure. (A) sCAC381; (B) sCAC22; (C) sCAC346; \& (D) sCAC3276. BuOH- butanol, BA- butyrate, NS- no stress, 30 \& 60 min post stress.

$[24,25]$. The differential expression of the sRNAs and their neighboring genes was analyzed by pairwise comparison of the no stress control sample against the three different levels of butanol or butyrate stress, (DEseq, $\mathrm{p}$-value $\leq 0.05$ ). Our analysis found very poor correlation between the differential expression of sRNAs and the neighboring genes (data not shown).

The clustered data were analyzed to identify shared regulatory elements, such as promoter sequences and transcription factor binding sites (TFBS) upstream of the sRNAs in the same cluster. Upstream regions of the sRNAs were scanned for putative promoter sites using B. subtilis position specific scoring matrices (PSSM) in the patser program within SIPHT [15] and the prokaryotic promoter prediction (PPP) tool for Lactococcus binding sites [46]. B. subtilis is the model $\mathrm{Gram}^{+}$organism, while the (also $\mathrm{Gram}^{+}$) Lactococcus model was used as it has a more similar $\mathrm{G}+\mathrm{C}$ content $(35 \%)$ to $C$. acetobutylicum (29\%). Using the B. subtilis model, we predicted that 52 of the 159 sRNAs (Additional file 1 \& [40]) contain putative $\sigma^{\mathrm{A}}, \sigma^{\mathrm{E}}, \sigma^{\mathrm{F}}$ and $\sigma^{\mathrm{G}}$ promoters. Using the PPP webtool led to the identification of previously known stress-related motifs. Specifically, we analyzed two upregulated sRNA clusters: B1 (sCAC3507 to sCAC3713, Figure 6B) and B2 (sCAC3184 to sCAC1128, Figure 6B); and two clusters containing downregulated sRNAs: $\mathrm{C}$ (Figure 6C) and $\mathrm{E}$ (Figure 6E). Motifs for $\sigma^{\mathrm{A}}$, the house-keeping sigma factor, were identified in the upstream regions for most of the sRNAs analyzed. In addition to $\sigma^{\mathrm{A}}$, the upstream regions of the four clusters were enriched in binding motifs for $\sigma^{\mathrm{B}}$ (the general-stress response sigma factor in B. subtilis; however no $\sigma^{\mathrm{B}}$ ortholog has been identified in C. acetobutylicum or any other Clostridium organism [47]) and transcriptional factor binding sites (TFBS) for transcriptional factors such as FlpAB (the FNR family transcriptional regulator - which has two C. acetobutylicum ortholog genes, CAC1511 \& CAP0082) [48,49], Llrb (two component system response regulator - with one $C$. acetobutylicum ortholog gene, CAC1700), Ahrc (arginine repressor - one C. acetobutylicum ortholog gene, CAC2074, coding for ArgR) (Foster, 2004) and Rex (redox sensing transcriptional repressor - one C. acetobutylicum ortholog gene, CAC2713) [50]. These proteins/ transcriptional regulators (Figure 8) and their regulons have been identified to be part of oxidative stress response in some, at least, prokaryotes, and this might explain the 


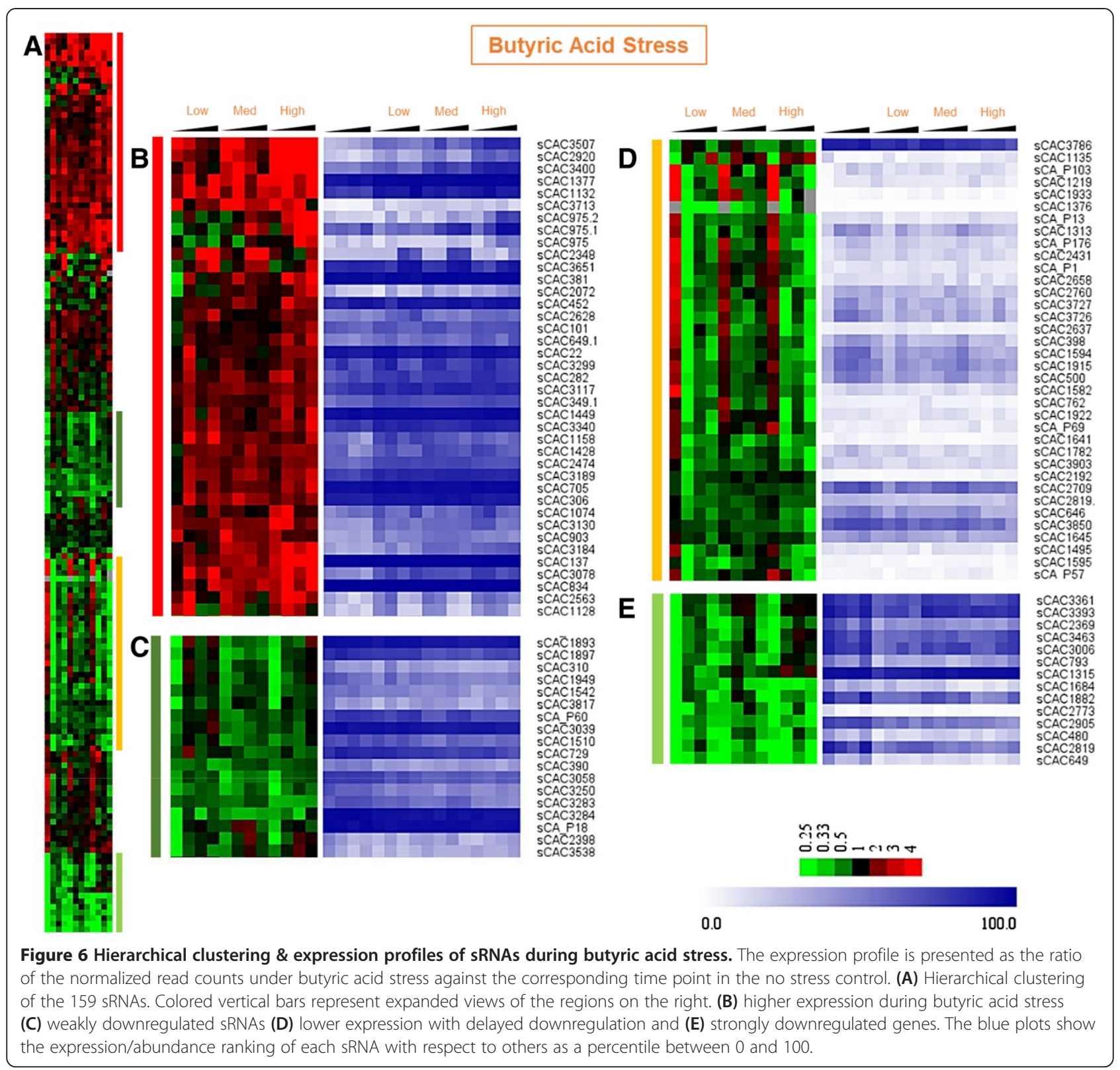

presence of these motifs on sRNA promoters differentially expressed under butyrate stress, which is frequently similar to oxidative-stress response [35]. Identification of regulatory elements in the differentially expressed sRNA clusters B1, B2, C and E (Figure 6) reveal the presence of both general stress responsive elements $\left(\sigma^{\mathrm{B}}\right)$ and the more specific oxidative stress response regulators (FNR, ArgR and Rex) supports the clustering of co-regulated stress responsive sRNAs.

\section{Hfq binding motifs on clostridial sRNAs}

In E. coli and a few other prokaryotes, it has been shown that activity of several sRNAs (and notably of many trans-acting sRNAs) requires the assistance of, or is enhanced by, the hexameric RNA chaperone Hfq [51-55]. Thus, we wanted to examine which of the 159 sRNAs in C. acetobutylicum might be Hfq targets, and if these putative targets might be responsive to metabolite stress.

sRNAs co-immunoprecipitated with Hfq contain the signature Hfq-binding motif and are designated as Hfqassociated sRNAs [11,12,55,56]. This binding motif was discovered largely based on the E. coli sRNAs, but appears to be valid in other organisms $[5,21,51,52,57]$ since the $\mathrm{Hfq}$ protein is well conserved among many prokaryotes. A structural CBLAST of the annotated C. acetobutylicum $\mathrm{Hfq}$ (CAC1834) with the two $\mathrm{Hfq}$ 


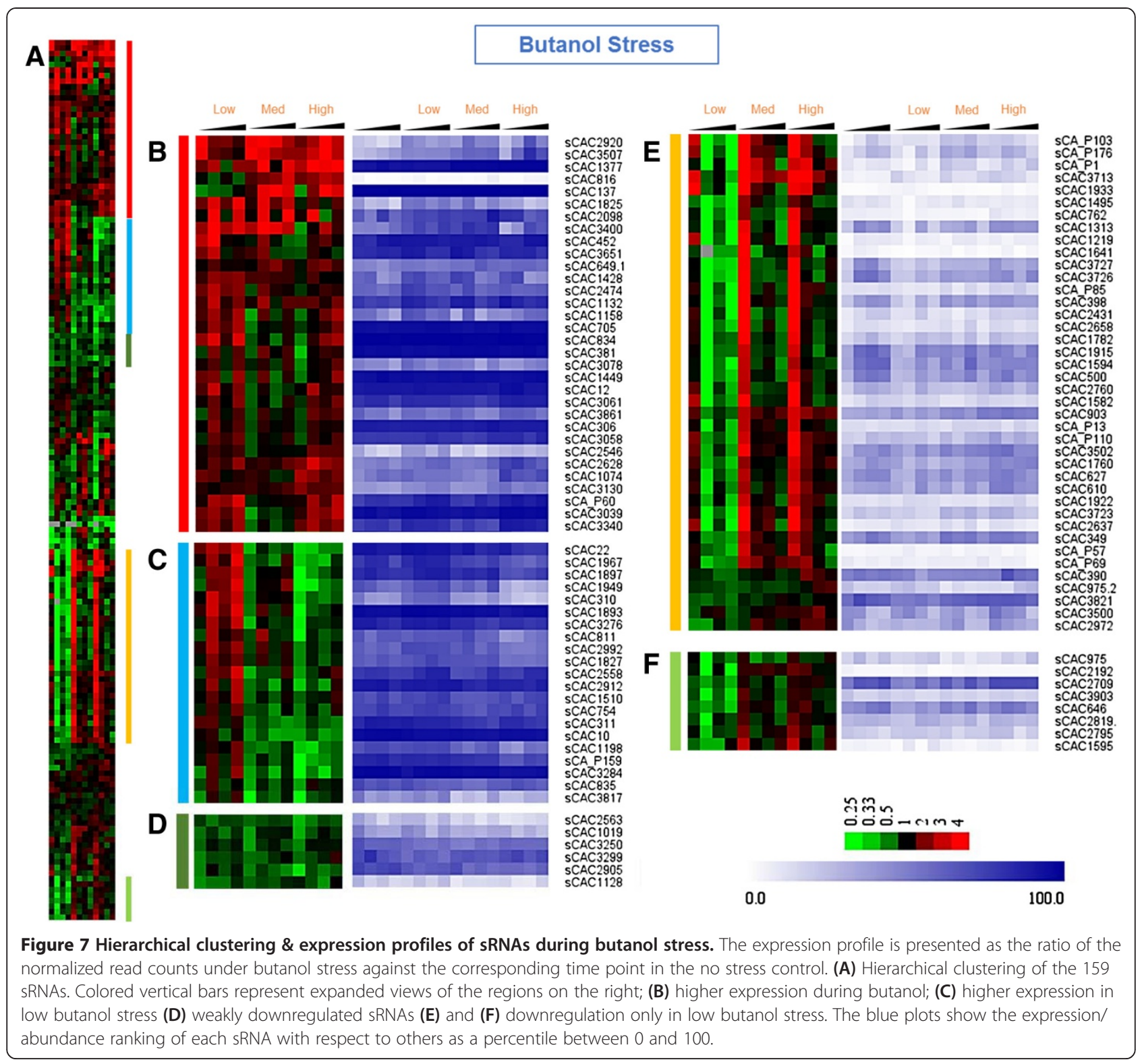

crystal structures, one from E. coli [58] (3GIB_B) and the other from S. aureus [54] (1KQ1_H), showed conservation in the sequence and the secondary structure of the Hfq monomeric unit (Additional file 3: Figure S1). Thus, we hypothesized that the binding motif of Hfq on sRNAs in E. coli might be preserved on sRNAs from C. acetobutylicum. This Hfq binding motif is characterized by U-rich regions, specifically a poly-U tail at the 3 ' end of the sRNA (downstream of the Rho independent terminator), and the U-rich or the AU-rich region upstream of the rho-independent terminator or other secondary hairpin structure; the 5 region of the sRNA is involved in (non-perfect) base-pairing with the target mRNA $[52,53,55]$. Using this model, we identified 65 potential
Hfq-associated sRNAs in C. acetobutylicum. Among these 65 sRNAs, 20 sRNAs belonged to the 46 newly identified sRNA from the deep sequencing data (Additional file 4). We clustered these putative $65 \mathrm{Hfq}$-associated sRNAs and found most of them to be differentially expressed under both butanol and butyrate stress (Additional file 5: Figure S2). The Hfq gene (CAC1834) was found to be mildly differentially expressed (upregulated) only under butanol stress.

Identification of the putative $\mathrm{Hfq}$ binding module on 65 sRNAs may prove useful for deconvoluting the stress-responsive regulatory network in Clostridia, since the unstructured 5' region of sRNAs that are targets of Hfq contains information that can be possibly 

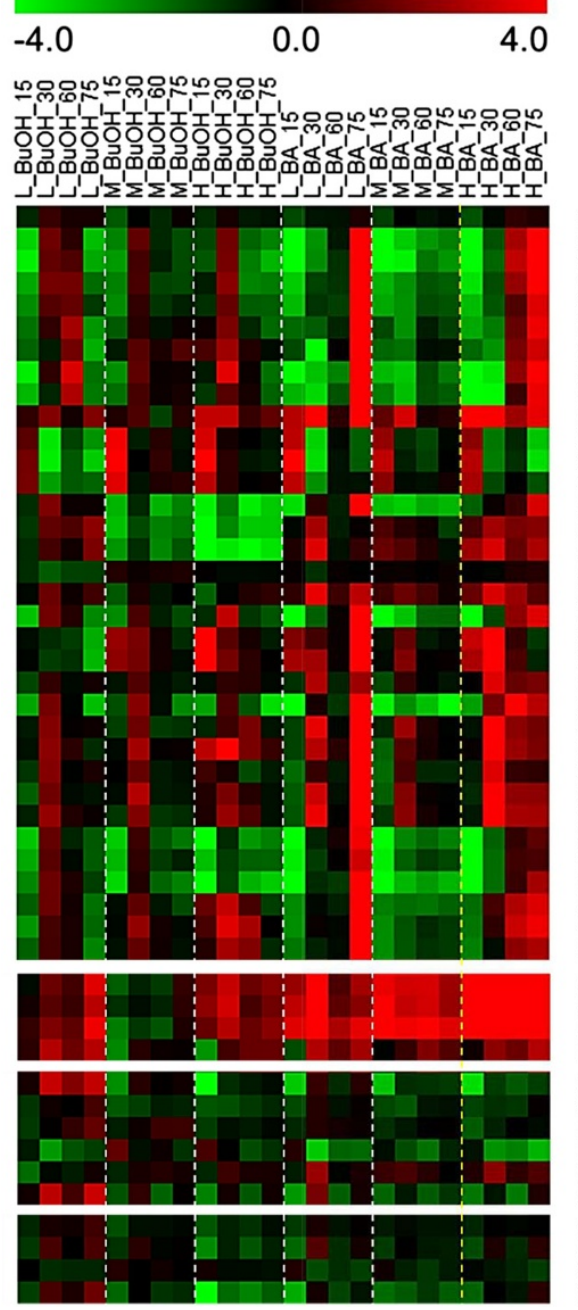

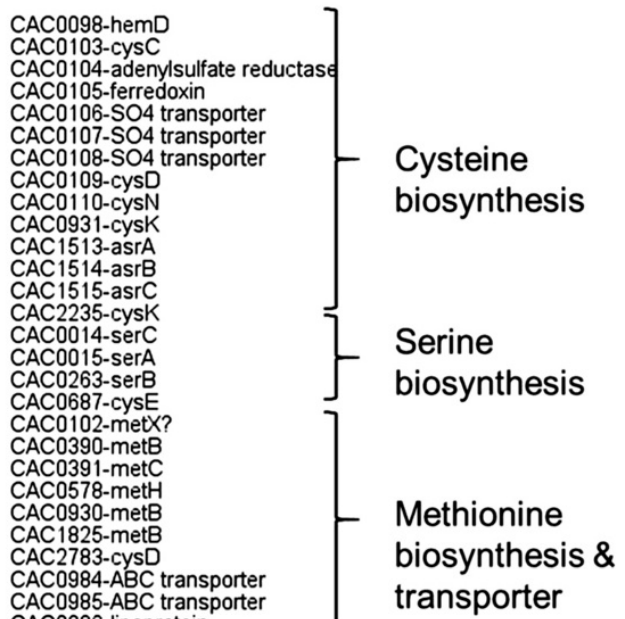

CACO

CAC0878-AA ABC transporter CAC0879-AA ABC transporter CAC0880-AA binding protein CAC3325-AA binding protein CAC 3326-AA ABC transporter CAC3327-AA ABC transporter CAP0162-adhe 1 CAP0163-ctfA CAP0164-ctfB CAP0165-adc CAC1834-hfq CAC2074-argR CAC1700-\|rb like CAC1511-FNR CAP0082-CRP regulatory protein CAC2713-rex CAC1754-Ffh CAC0716-smpB CAC1964-rpsA CAC3136-tuf

\section{sRNA associated proteins}

Figure 8 Expression profile of genes involved in sulfur amino acid metabolism; part of the sol operon; and genes coding for Hfq and other regulatory proteins (see text for details).

used to identify potential target mRNAs of these sRNAs [59].

\section{Differentially expressed sRNAs that can be related to} physiological events of the metabolite-stress response: SRP RNA, 6S RNA, tmRNA, SAM RNA and solB (sCAP_176)

The data presented above showing a large number of sRNAs exhibiting differential expression under metabolite stress provides strong evidence that sRNAs are an integral part of the clostridial stress response system. While the detailed action of these sRNAs remains to be elucidated, there are several sRNAs whose action can be readily related to the phenotypic response of these cells to metabolite stress affecting various metabolic pathways as previously shown $[35,37,39,42,60]$ and further confirmed by the present set of RNA-seq data as well as the accompanying large set of new microarray and proteomic data [61].
Both butanol and butyrate stress affect membrane physiology and homeostasis by reducing the transmembrane electrochemical potential and proton gradient $(\Delta \mathrm{pH})$ $[33,34,62]$. Bacteria respond to the toxicity of these metabolites by altering the membrane composition by increasing the percentage of saturation in the lipid tails and also by incorporating various integral membrane and transport proteins [63]. We have previously shown that the signal recognition particle (SRP) system and upregulation of several membrane proteins are apparently important in imparting butyric-acid tolerance [34]. The SRP, which consists of the SRP RNA and the Ffh protein, recognizes a motif on mRNAs coding for membrane proteins and, thus, transports the corresponding ribosomes to the membrane to synthesize the targeted proteins [64]. In this light, upregulation of the $4.5 S S R P-R N A$ (Figures $6 \& 7$ ) is consistent with its role in the biosynthesis and localization of membrane proteins and the role of membrane proteins in 
metabolite stress response and tolerance [34]. The Ffh gene is not differentially expressed under metabolite stress (Figure 8), thus further supporting its role as a housekeeping protein.

C. acetobutylicum, like other Clostridium organisms and most prokaryotes, reorganizes its transcriptional and translational machineries during the transition from exponential to stationary phase of growth and under stress conditions [35,37,38,42,45,47,60,65]. Downregulation of non-essential transcripts and overexpression of different transcript sets requires a quick turnover in the engagement of sigma factors. The 6S RNA (also known as SsrS RNA) has been shown to negatively regulate the transcripts under the control of the major sigma factor $\sigma^{70}$ in E. coli and B. subtilis (where it is better known as $\sigma^{\mathrm{A}}$ ) during the stationary phase of growth by interacting with the RNA polymerase holoenzyme [66]. 6S RNA has been found to be important in cell survival under stress in both $E$. coli and B. subtilis $[67,68]$. We have previously shown that the 6S RNA in $C$. acetobutylicum, which displays the conserved secondary structure (Figure 4A) of an asymmetric bubble [69], is expressed at high levels [40]. Its Northern blot (Figure 4A) confirms its strong expression and displays multiple bands, which correspond to distinct processed RNA forms as in other prokaryotes $[66,69]$. In contrast to previously reported $6 \mathrm{~S}$ RNAs displaying two sRNA forms of distinct size, here the 6S sRNA displays three bands (Figure 4A). 6S RNA acts as a template for binding of $\sigma^{70}$, and is thus capable, when upregulated, of titrating $\sigma^{70}$ thus leading to downregulation of genes under $\sigma^{70}$ control. This stress responsive role of 6S RNA has been established in E. coli $[70,71]$, and our data support that it has a similar role in C. acetobutylicum. It is notable that the $6 \mathrm{~S}$ sRNA here contains the two characteristic central bubbles with a short stem loop attached [72]. The two components of the $\sigma^{\mathrm{A}}$ (the $\sigma^{70}$ in C. acetobutylicum) binding motif (UUGACA [-35] \& UAUAAU [-10], which corresponds to the DNA motif TTGACA and TATAAT) are found to be perfectly preserved, one on each of the central asymmetric bubbles (Figure 4A), thus apparently regulating the transcriptional responses to metabolite and other stresses. It is interesting to note that in Legionella pneumophila, 6S RNA was found to regulate the expression of secretion system effectors, and stress response proteins such as GroES and RecA [73]. As discussed, the GroESL system is one of the most upregulated HSP systems under a broad spectrum of stresses in Clostridium organisms.

The transfer-messenger RNA (tmRNA or SsrA RNA, which has both tRNA- and mRNA like properties) together with 3 proteins (small protein $B$ [SmpB], elongation factor $\mathrm{Tu}[\mathrm{EF}-\mathrm{Tu}]$, and ribosomal protein $\mathrm{S} 1$ ) forms the tmRNP complex. The tmRNP complex is involved in the quality- control, so-called trans-translation process, recycling stalled ribosomes and facilitating the degradation of aberrant proteins and mRNAs $[74,75]$. Trans-translation is especially important in the transition between growth phases and under stress conditions [75-77], whereby many ribosomes may stall on damaged or partially degraded mRNAs. In this context, the stress-induced upregulation (Figures 4B, $6 \&$ 7) of the $C$. acetobutylicum tmRNA (sCAC834) confirms its role in the quality-control process of trans-translation. It is worth noting that tmRNA is one of the most highly expressed sRNAs in these experiments (blue plots of Figures 6 \& 7), further confirming its critical roles for the trans-translation process under stress. Of note, none of the three proteins (CAC0716 - smpB, SsrA-binding protein; CAC1964 - rpsA, 30S ribosomal protein S1; \& CAC3136 - tuf, elongation factor $\mathrm{Tu}$ ) of the tmRNP complex appear to be differentially expressed under stress (Figure 8), thus suggesting that the tmRNA upregulation is controlling the trans-translation process under stress. This is the first experimental evidence for the expression and role of a tmRNA in a Clostridium organism. Deletion of tmRNA in Streptomyces coelicolor was shown [78,79] to affect the translation of proteins that play a vital role in survival such as cell-cycle and stress proteins including the major HSP protein DnaK, a protein universally engaged in the stress response of Clostridium organisms as already discussed.

S-box (SAM) and T-box riboswitches regulate the expression of genes involved in the metabolism of cysteine and methionine in C. acetobutylicum and are typically found adjacent to the genes involved in sulfur amino acid metabolism [80]. S-box, which is dependent on the concentration of s-adenosyl methionine (SAM), has been shown to regulate the expression of genes in methionine metabolism through transcriptional anti-terminator systems [80]. In C. acetobutylicum, genes involved in sulfur metabolism were found to be upregulated (Figure 8) during high levels of acid stress. We note that an earlier study from our lab had reported that under acid stress, the genes involved in cysteine, methionine and serine metabolism were downregulated [35]; this difference between the two studies can be attributed to the role of proton concentration since in this present study, in contrast to the earlier one, we used $\mathrm{pH}$ control in the fermentation experiments.

Solventogenesis in C. acetobutylicum is controlled by the pSOL1-megaplasmid borne genes (adhE1(aad)-ctfA-ctfB) of the sol operon and the convergent monocistronic adc operon [81,82]. Expression of the sol operon is dependent on Spo0A [83] but other genes are also involved in regulating its expression through a long 5' UTR, which appears like a good target for sRNA regulation. solB (sCAP_176), located just upstream of the sol operon, has been 
identified as the putative repressor of the sol operon and thus of solventogenesis [84]. Although expressed at very low levels (Figures $6 \& 7$ ), solB appears to be a very potent repressor: upon $s o l B$ inactivation (originally achieved by inactivating the adjacent gene CAP0161 [85]), solvent formation starts earlier and leads to considerably higher levels of solvents [86]. Thus, solB downregulation promotes sol mRNA expression and solvent production, and vice versa. Here, we found that $s o l B$ is downregulated (Figure 6D) under butyrate stress, except for the first time point (15 min post stress). Accordingly, the sol-operon genes display a strong upregulation pattern (Figure 8). Butanol stress leads to a more complex pattern of solB expression (Figure 7E), thus leading to a largely opposite expression of the sol-operon genes, except for the first two time points of the high butanol stress (Figure 8). Schiel et al. (2010) reported a putative antisense binding of the $\mathrm{solB}$ repressor to the upstream region of the sol operon [87] (Additional file 6: Figure S3).

\section{Conclusions}

The goal of this study was to identify sRNAs that respond to butanol and/or butyrate stress, and also general stress, since, as we discussed, it was previously shown that toxic-chemical stress in Clostridium organisms engages both the general HSP systems as well as specialized systems. One can logically argue that the sRNAs that are differentially expressed under both butanol and butyrate stress would belong to the general stress response. In this sense, the putative roles of SRP RNA, $6 S R N A, t m R N A$ and $S A M R N A$ are part of the general stress response, but perhaps $s o l B$ belongs to the specialized stress response (Figures 6, 7 \& Additional file 7: Figure S4). The metabolite-stress sRNome in $C$. acetobutylicum was investigated using deep RNA sequencing, in combination with computational analyses. 46 novel sRNAs were identified. The sRNA expression patterns under different levels of butanol and butyrate stress strongly support a role of many sRNAs in orchestrating stress-related cellular changes to deal with the complex, pleiotropic effects of the toxic metabolite stress. This is further supported by the fact that $7.5 \%$ of the RNA-seq reads map to non-annotated IOR and IGR of the genome. This is the first comprehensive study of genome-scale expression of sRNAs in a Clostridium or any organism under metabolite stress. Use of extensive temporal RNA-seq data in combination with computational predictions and Northern-based assays are essential in reaching robust outcomes in identifying previously unexplored sRNAs. These data can be used for understanding the role of sRNAs in regulating growth and metabolism thus aiming to provide a more comprehensive understanding of the regulatory network of the cell, and how that network can be engineered for practical applications to produce chemicals and fuels or for remediation processes.

\section{Methods}

\section{Strain and growth conditions}

Three biological replicate cultures of C. acetobutylicum ATCC 824 were carried out in $\mathrm{pH}$ - controlled $(\mathrm{pH}>5)$ batch fermentations in $4 \mathrm{~L}$ bioreactors (Bioflow II and 110, New Brunswick Scientific, Edison, NJ, USA) in a defined clostridial growth media [61]. The cultures were stressed with butanol (30 mM, $60 \mathrm{mM}$ and $90 \mathrm{mM})$ and butyric acid (30 mM, $40 \mathrm{mM}$ and $50 \mathrm{mM}$ ) at midexponential phase of growth at an OD of 1.0 and were sampled at 4 different time points: $15 \mathrm{~min}, 30 \mathrm{~min}$, $60 \mathrm{~min}$ and $75 \mathrm{~min}$ post stress. Parallel cultures $(\mathrm{n}=3)$ that were exposed to neither stress were used as the non-stress controls.

\section{RNA isolation and construction of CDNA libraries for RNA-} seq

Samples for RNA isolation were collected by centrifugation at $5000 \mathrm{rpm}$ at $4^{\circ} \mathrm{C}$ for $10 \mathrm{~min}$ and the pellets were stored at $-80^{\circ} \mathrm{C}$. RNA isolation was carried out using the Qiagen's miRNeasy Mini kit [45]. After RNA extraction, mRNA and sRNA were enriched by using Microbe Express kit from Ambion ${ }^{\oplus}$ kit as per the manufacturer's protocol. The Ovation Prokaryotic RNA-Seq System (NuGEN ${ }^{\oplus}$ Technologies, Inc, San Carlos, CA) was used to synthesize cDNA from $500 \mathrm{ng}$ of enriched RNA. In brief, $2 \mu \mathrm{L}$ of first primer mix was added to the $500 \mathrm{ng}$ of the RNA and incubated at $65^{\circ} \mathrm{C}$ for $5 \mathrm{~min}$. Later, $10 \mu \mathrm{L}$ of the master mix (first strand buffer and enzyme) were added to the above reaction for first strand synthesis followed by the purification of the first strand cDNA using the QiaQuick PCR purification kit (QIAGEN, Inc. Valencia, CA). The last step of cDNA synthesis was synthesizing the $2^{\text {nd }}$ strand, which was then purified using the Minelute Reaction clean up kit (QIAGEN ${ }^{\circ}$ ) and eluted in $10 \mu \mathrm{L}$ of elution buffer. The elution buffer was used to make up the volume of the cDNA to $50 \mu \mathrm{L}$. The resulting $50 \mu \mathrm{L}$ of cDNA was used to construct libraries using the TruSeq DNA Sample preparation kit (Illumina San Diego, CA). In brief, the cDNA underwent end repair, 3 ' end adenylation, adapter ligation and enrichment. Clean up of DNA fragments after each process were carried out using AMPure XP Beads. The fragment length of the libraries was checked using a Bioanalyzer before loading onto HiSeq 2000.

\section{RNA sequencing and data analyses}

Deep sequencing was performed using Illumina's HiSeq 2000 with a read length of $50 \mathrm{bp}$, generating individual library sequence files. Sequence files were processed to remove barcodes, trim adapters, and count read abundances using a set of custom perl, python, and MySQL scripts. Reads were mapped to the $C$. acetobutylicum genome using Tophat [88]. Gene annotations were 
downloaded from NCBI, and predicted sRNA regions were included from Chen et al. [40]. Differential expression analysis of sRNAs was performed using DESeq, part of the R Bioconductor package [89]. Differentially expressed sRNAs were determined at a $\mathrm{p}$-value $\leq 0.05$, for a pairwise comparison between the control library set and any of the six stress groups (low, medium, and high butanol and low, medium, and high butyrate). Interoperonic regions were defined using previously predicted operons [43]. The data was submitted to Gene Expression Omnibus (GEO) and can be accessed with the accession number GSE48349.

\section{Prediction of novel sRNAs using RNA-seq data}

The IORs used in this study were the same as those identified and used by Chen et al. for predicting the 113 sRNAs in C. acetobutylicum [40]. Identification of new sRNAs was based on selecting interoperonic regions (IORs) with a minimal read count of 50 . This metric was assigned based on the analysis of the RNA-seq data for mRNAs and sRNAs (Figure 1). Only IORs that met the criteria of a minimal read count were considered for further analysis. Computational prediction of sRNAs was performed using SIPHT based on the comparative analysis of the 21 Clostridium genomes in NCBI. The previously identified 113 sRNAs [40] were removed for predicting novel sRNAs. Thus, IORs expressed at a minimal read count of 50 and were also computationally predicted to contain sRNAs in the expressed IORs, were manually curated to eliminate false positives. False positives were defined as IORs, which had predominant expression only from the untranslated region (UTRs) of the neighboring genes, even though sRNAs were computationally predicted in those regions. Identification of false positives was carried out using a custom web viewer (generated using custom PHP scripts) by visually analyzing RNA-seq data.

\section{Northern analysis}

Northern analysis of select sRNAs was performed as described previously using single stranded oligo DNA probes [40]. The probes used in Northern analysis are listed in Additional file 2: Table S2. For each lane, $10 \mu \mathrm{g}$ of total RNA was loaded in a $5 \%$ precast polyacrylamide Ready Gel TBE-urea (Bio-Rad, Hercules, CA), and was electrophoretically resolved along with molecular markers of single stranded RNA ranging from $50 \mathrm{nt}$ to $1000 \mathrm{nt}$ (New England Biolabs, Ipswich, MA). Following electrophoresis, the RNA was transferred to a BrightStar-Plus positively charged nylon membrane (Ambion). Probes were labeled with ATP $\left[\gamma^{32} \mathrm{P}\right]$ using Optikinase (USB, Cleveland, $\mathrm{OH}$ ) and the unincorporated radioactive material was removed using Micro Bio-Spin Column (Bio-Rad, Hercules, CA). The prehybridization and hybridization of the membrane with labeled oligo probes was carried using the ULTRAhyb hybridization solution (Ambion) at $42^{\circ} \mathrm{C}$.

\section{Promoters and Rho-independent terminators of sRNAs}

Promoter prediction in the upstream region of the sRNAs were carried out using PSSMs of B. subtilis promoter consensus sequences [15]. For the Lactococcus promoters, we used the promoter HMM model from the PPP tool [46]. Rho independent terminators were predicted using RNAmotif [90], Erpin [91] and Findterm (www.softberry.com). Secondary structures of sRNAs were predicted using Vienna RNAfold [92,93].

\section{sRNA nomenclature}

The sRNA nomenclature for the newly identified sRNAs was done in the same manner as described previously [40].

\section{Additional files}

Additional file 1: Detailing the information on the sequenced libraries and the list of newly identified 46 sRNAs.

Additional file 2: Table S1. Differential expression of annotated mRNAs of $C$. acetobutylicum. Pair-wise and point by point by comparison of each stress level to the no stress control using DEseq at a p-value $\leq 0.05$.

Table S2: Probes sequences used for Northern analysis.

Additional file 3: Figure S1. CBLAST of the C. acetobutylicum hfo (CAC1834, gi 15895109) with the Hfa from E. coli (3GIB B), reveals conservation in the secondary structure on the $\mathrm{Hfq}$ monomeric unit (A) The $a-\beta_{1-5}$ structural unit can be found to be conserved. (B) The corresponding conservation in the protein sequence is displayed below.

Additional file 4: Containing the $\mathrm{Hfq}$ binding model.

Additional file 5: Figure S2. Hierarchical clustering of the 65 sRNAs belonging to the Hfq constellation (see text for details).

Additional file 6: Figure S3. Putative antisense binding of $s o l B$ to the sol (adhE1-ctfA-ctfB) operon.

Additional file 7: Figure S4. Hierarchical clustering of 159 sRNAs under both butanol and butyric acid stress.

\section{Abbreviations}

SIPHT: sRNA identification protocol using high-throughput technologies; ABE: Acetone-bytanol-ethanol; Q-RT-PCR: Quantitative reverse transcriptase polymerase chain reaction; IOR: Interoperonic region; IGR: Intergenic region; ORF: Open reading frame; UTR: Untranslated region; PSSM: Position specific scoring matrix; HMM: Hidden Markov model; FNR: Ferredoxin-NADP ${ }^{+}$ reductase; AhrC/ArgR: Arginine repressor; Hfq: Host factor-I protein from Q8 bacteriophage; TFBS: Transcriptional factor binding site; SRP: Signal recognition particle; tmRNA: Transfer and messenger RNA; SAM: S-adenosyl methionine; adhe: Alcohol/aldehyde dehydrogenase 1; ctf: Co-enzyme A transferase; adc: Acetoacetate decarboxylase; SmpB: Small protein B; EF-Tu/Tuf: Elongation factor Tu; rpsA: Ribosomal protein A.

\section{Competing interests}

The authors declare that they have no competing interests.

\section{Authors' contributions}

KPV and SWJ carried out the fermentations and RNA isolations. KPV carried out Northern analysis and drafted the manuscript. SGK constructed the libraries for RNA-seq. KPM processed the data and built the web browser. KPV and KPM analysed the data. KPV and MTR carried out the identification of new SRNAs and other computational analyses. BCM and ETP helped with data analysis and interpretation, and participated in the manuscript preparation. ETP conceived the study, participated in its design and coordination. All authors read and approved the final manuscript. 


\section{Acknowledgements}

We acknowledge the assistance of Dinesh Indurthi in training KPV for Northern analysis and members of Papoutsakis laboratory for their assistance during sampling of the cultures for RNA isolation. The work was supported by the genomic sciences grant from Department of Energy, USA (grant\# DESC0007092)

\section{Author details}

${ }^{1}$ Department of Chemical and Biomolecular Engineering, University of Delaware, Newark, DE, USA. ${ }^{2}$ Delaware Biotechnology Institute, University of Delaware, Newark, DE, USA. ${ }^{3}$ Department of Computer and Information Sciences, University of Delaware, Newark, DE, USA. ${ }^{4}$ Department of Plant and Soil Sciences, University of Delaware, Newark, DE, USA. ${ }^{5}$ Center for Bioinformatics and Computational Biology, University of Delaware, Newark, DE, USA

Received: 19 July 2013 Accepted: 14 November 2013 Published: 4 December 2013

\section{References}

1. Argaman L, Hershberg R, Vogel J, Bejerano G, Wagner EGH, Margalit H, Altuvia S: Novel small RNA-encoding genes in the intergenic regions of Escherichia coli. Curr Biol 2001, 11(12):941-950.

2. Brownlee GG: Sequence of 6s RNA of E. coli. Nature-New Biol 1971, 229(5):147.

3. Hindley J: Fractionation of 32P-labelled ribonucleic acids on polyacrylamide gels and their characterization by fingerprinting. J Mol Bio/ 1967, 30(1):125-136.

4. Storz G, Haas D: A guide to small RNAs in microorganisms. Curr Opin Microbiol 2007, 10(2):93-95.

5. Lenz DH, Mok KC, Lilley BN, Kulkarni RV, Wingreen NS, Bassler BL: The small RNA chaperone $\mathrm{Hfq}$ and multiple small RNAs control quorum sensing in Vibrio harveyi and Vibrio cholerae. Cell 2004, 118(1):69-82.

6. Livny J, Brencic A, Lory S, Waldor MK: Identification of 17 Pseudomonas aeruginosa sRNAs and prediction of sRNA-encoding genes in 10 diverse pathogens using the bioinformatic tool sRNAPredict2. Nucleic Acids Res 2006, 34(12):3484-3493.

7. Shinhara A, Matsui M, Hiraoka K, Nomura W, Hirano R, Nakahigashi K, Tomita M, Mori H, Kanai A: Deep sequencing reveals as-yet-undiscovered small RNAs in Escherichia coli. BMC Genomics 2011, 12:428.

8. Irnov I, Sharma CM, Vogel J, Winkler WC: Identification of regulatory RNAs in Bacillus subtilis. Nucleic acids research 2010, 38(19):6637-6651.

9. Mraheil MA, Billion A, Mohamed W, Mukherjee K, Kuenne C, Pischimarov J, Krawitz C, Retey J, Hartsch T, Chakraborty T, et al: The intracellular sRNA transcriptome of Listeria monocytogenes during growth in macrophages. Nucleic Acids Res 2011, 39(10):4235-4248.

10. Patenge N, Billion A, Raasch P, Normann J, Wisniewska-Kucper A, Retey J, Boisguerin $\mathrm{V}$, Hartsch T, Hain T, Kreikemeyer B: Identification of novel growth phase- and media-dependent small non-coding RNAs in Streptococcus pyogenes M49 using intergenic tiling arrays. BMC Genomics 2012, 13:550.

11. Sittka A, Lucchini S, Papenfort K, Sharma CM, Rolle K, Binnewies T, Hinton JCD, Vogel J: Deep Sequencing Analysis of Small Noncoding RNA and mRNA Targets of the Global Post-Transcriptional Regulator, Hfq. PLOS Genet 2008, 4(8):e1000163. doi:10.1371/journal.pgen.1000163.

12. Sittka A, Sharma CM, Rolle K, Vogel J: Deep sequencing of Salmonella RNA associated with heterologous Hfq proteins in vivo reveals small RNAs as a major target class and identifies RNA processing phenotypes. RNA Biol 2009, 6(3):266-275.

13. Wilms I, Overloper A, Nowrousian M, Sharma CM, Narberhaus F: Deep sequencing uncovers numerous small RNAs on all four replicons of the plant pathogen Agrobacterium tumefaciens. RNA Bio/ 2012, 9(4):446-457.

14. Livny J, Waldor MK: Identification of small RNAs in diverse bacterial species. Curr Opin Microbiol 2007, 10(2):96-101.

15. Livny J, Fogel MA, Davis BM, Waldor MK: sRNAPredict: an integrative computational approach to identify sRNAs in bacterial genomes. Nucleic Acids Res 2005, 33(13):4096-4105.

16. Rivas E, Eddy SR: Noncoding RNA gene detection using comparative sequence analysis. BMC Bioinformatics 2001, 2(1):8.
17. Pichon C, Felden B: Intergenic sequence inspector: searching and identifying bacterial RNAs. Bioinformatics 2003, 19(13):1707-1709.

18. Sridhar J, Narmada SR, Sabarinathan R, Ou HY, Deng ZX, Sekar K, Rafi ZA, Rajakumar K: sRNAscanner: A Computational Tool for Intergenic Small RNA Detection in Bacterial Genomes. PloS One 2010, 5(8). e11970. doi: 10.1371/journal.pone.0011970.

19. Domenech P, Honore N, Heym B, Cole ST: Role of OxyS of Mycobacterium tuberculosis in oxidative stress: overexpression confers increased sensitivity to organic hydroperoxides. Microbes Infect 2001, 3(9):713-721.

20. Mey AR, Craig SA, Payne SM: Characterization of Vibrio cholerae RyhB: the RyhB regulon and role of ryhB in biofilm formation. Infect Immun 2005, 73(9):5706-5719.

21. Davis BM, Quinones M, Pratt J, Ding YP, Waldor MK: Characterization of the small untranslated RNA RyhB and its regulon in Vibrio cholerae. J Bacteriol 2005, 187(12):4005-4014.

22. Gottesman S, McCullen C, Guillier M, Vanderpool C, Majdalani N, Benhammou J, Thompson K, FitzGerald P, Sowa N, FitzGerald D: Small RNA regulators and the bacterial response to stress. Cold Spring Harb Symp Quant Biol 2006, 71:1-11. 10.1101/sqb.2006.71.016.

23. Negrete $\mathrm{A}, \mathrm{Ng} \mathrm{Wl}$, Shiloach J: Glucose uptake regulation in $E$. coli by the small RNA SgrS: comparative analysis of E. coli K-12 (JM109 and MG1655) and E. coli B (BL21). Microb Cell Fact 2010, 9:75. 10.1186/1475-2859-9-75.

24. Battesti A, Majdalani N, Gottesman S: The RpoS-Mediated General Stress Response in Escherichia coli. Annu Rev Microbiol 2011, 65:189-213.

25. Mandin P, Gottesman S: Integrating anaerobic/aerobic sensing and the general stress response through the ArcZ small RNA. EMBO J 2010, 29(18):3094-3107.

26. Repoila F, Majdalani N, Gottesman S: Small non-coding RNAs, co-ordinators of adaptation processes in Escherichia coli: the RpoS paradigm. Mol Microbiol 2003, 48(4):855-861.

27. Tracy BP, Jones SW, Fast AG, Indurthi DC, Papoutsakis ET: Clostridia: the importance of their exceptional substrate and metabolite diversity for biofuel and biorefinery applications. Curr Opin Biotechnol 2012, 23(3):364-381.

28. Fast AG, Papoutsakis ET: Stoichiometric and energetic analyses of non-photosynthetic $\mathrm{CO} 2$-fixation pathways to support synthetic biology strategies for production of fuels and chemicals. Curr Opin Chem Eng 2012, 1(4):380-395.

29. Morgan XC, Tickle TL, Sokol H, Gevers D, Devaney KL, Ward DV, Reyes JA, Shah SA, LeLeiko N, Snapper SB, et al: Dysfunction of the intestinal microbiome in inflammatory bowel disease and treatment. Genome Biol 2012, 13(9):R79.

30. Alvarez-Ordonez A, Mouwen DJM, Lopez M, Prieto M: Fourier transform infrared spectroscopy as a tool to characterize molecular composition and stress response in foodborne pathogenic bacteria. J Microbiol Meth 2011, 84(3):369-378.

31. Chowdhury R, Sahu GK, Das J: Stress response in pathogenic bacteria. J Biosci 1996, 21(2):149-160.

32. Hassett DJ, Cohen MS: Bacterial Adaptation to Oxidative Stress - Implications for Pathogenesis and Interaction with Phagocytic-Cells. FASEB J 1989, 3(14):2574-2582.

33. Nicolaou SA, Gaida SM, Papoutsakis ET: A comparative view of metabolite and substrate stress and tolerance in microbial bioprocessing: From biofuels and chemicals, to biocatalysis and bioremediation. Metab Eng 2010, 12(4):307-331.

34. Borden JR, Jones SW, Indurthi D, Chen Y, Papoutsakis ET: A genomic-library based discovery of a novel, possibly synthetic, acid-tolerance mechanism in Clostridium acetobutylicum involving non-coding RNAs and ribosomal RNA processing. Metab Eng 2010, 12(3):268-281.

35. Alsaker KV, Paredes C, Papoutsakis ET: Metabolite stress and tolerance in the production of biofuels and chemicals: gene-expression-based systems analysis of butanol, butyrate, and acetate stresses in the anaerobe Clostridium acetobutylicum. Biotechnol Bioeng 2010, 105 (6):1131-1147.

36. Gaida SM, Al-Hinai MA, Indurthi D, Nicolaou SA, Papoutsakis ET: Synthetic tolerance: three noncoding small RNAs, DsrA, ArcZ and RprA, acting supraadditively against acid stress. Nucleic Acids Res 2013, 41. 10.1093/nar/gkt1651.

37. Janssen $\mathrm{H}$, Grimmler $\mathrm{C}$, Ehrenreich $\mathrm{A}$, Bahl H, Fischer RJ: A transcriptional study of acidogenic chemostat cells of Clostridium acetobutylicum-Solvent stress caused by a transient n-butanol pulse. J Biotechno/ 2012, 161(3):354-365. 
38. Alsaker KV, Spitzer TR, Papoutsakis ET: Transcriptional analysis of spo0A overexpression in Clostridium acetobutylicum and its effect on the cell's response to butanol stress. J Bacterio/ 2004, 186(7):1959-1971.

39. Tomas CA, Beamish J, Papoutsakis ET: Transcriptional analysis of butanol stress and tolerance in Clostridium acetobutylicum. J Bacteriol 2004, 186(7):2006-2018.

40. Chen Y, Indurthi DC, Jones SW, Papoutsakis ET: Small RNAs in the genus Clostridium. Ambio 2011, 2(1):e00340-00310. 10.1128/mBio.00340-10.

41. Nicolaou SA, Gaida SM, Papoutsakis ET: Coexisting/Coexpressing Genomic Libraries (CoGeL) identify interactions among distantly located genetic loci for developing complex microbial phenotypes. Nucleic Acids Res 2011, 39(22):e152.

42. Alsaker KV, Papoutsakis ET: Transcriptional program of early sporulation and stationary-phase events in Clostridium acetobutylicum. J Bacterio 2005, 187(20):7103-7118.

43. Paredes CJ, Rigoutsos I, Papoutsakis ET: Transcriptional organization of the Clostridium acetobutylicum genome. Nucleic Acids Res 2004 32(6):1973-1981.

44. Komine Y, Kitabatake M, Yokogawa T, Nishikawa K, Inokuchi H: A TransferRna-Like Structure Is Present in 10sa Rna, a Small Stable Rna from Escherichia coli. Proc Natl Acad Sci USA 1994, 91(20):9223-9227.

45. Jones SW, Paredes CJ, Tracy B, Cheng N, Sillers R, Senger RS, Papoutsakis ET: The transcriptional program underlying the physiology of clostridial sporulation. Genome Biol 2008, 9(7):R114.

46. Zomer AL, Buist G, Larsen R, Kok J, Kuipers OP: Time-resolved determination of the CcpA regulon of Lactococcus lactis subsp cremoris MG1363. J Bacteriol 2007, 189(4):1366-1381

47. Paredes CJ, Alsaker KV, Papoutsakis ET: A comparative genomic view of clostridial sporulation and physiology. Nat Rev Microbio/ 2005, 3(12):969-978

48. Akhter $Y$, Tundup S, Hasnain SE: Novel biochemical properties of a CRP/ FNR family transcription factor from Mycobacterium tuberculosis. Int J Med Microbiol 2007, 297(6):451-457.

49. Kazakov AE, Rodionov DA, Price MN, Arkin AP, Dubchak I, Novichkov PS: Transcription Factor Family-Based Reconstruction of Singleton Regulons and Study of the Crp/Fnr, ArsR, and GntR Families in Desulfovibrionales Genomes. J Bacteriol 2013, 195(1):29-38.

50. Wietzke M, Bahl H: The redox-sensing protein Rex, a transcriptional regulator of solventogenesis in Clostridium acetobutylicum. Appl Microbiol Biotechnol 2012, 96(3):749-761.

51. Vogel J, Luisi BF: Hfq and its constellation of RNA. Nat Rev Microbio/ 2011, 9(8):578-589.

52. Otaka H, Ishikawa $H$, Morita T, Aiba H: PolyU tail of rho-independent terminator of bacterial small RNAs is essential for $\mathrm{Hfq}$ action. Proc Natl Acad Sci USA 2011, 108(32):13059-13064.

53. Papenfort K, Bouvier M, Mika F, Sharma CM, Vogel J: Evidence for an autonomous 5 ' target recognition domain in an $\mathrm{Hfq}$-associated small RNA. Proc Natl Acad Sci U S A 2010, 107(47):20435-20440.

54. Schumacher MA, Pearson RF, Moller T, Valentin-Hansen P, Brennan RG: Structures of the pleiotropic translational regulator $\mathrm{Hfq}$ and an Hfq-RNA complex: a bacterial Sm-like protein. EMBO J 2002, 21(13):3546-3556

55. Ishikawa H, Otaka H, Maki K, Morita T, Aiba H: The functional Hfq-binding module of bacterial sRNAs consists of a double or single hairpin preceded by a U-rich sequence and followed by a 3 ' poly(U) tail. RNA 2012, 18(5):1062-1074

56. Ikeda Y, Yagi M, Morita T, Aiba H: Hfq binding at RhlB-recognition region of RNase $E$ is crucial for the rapid degradation of target mRNAs mediated by sRNAs in Escherichia coli. Mol Microbio/ 2011, 79(2):419-432.

57. Brennan RG, Link TM: Hfq structure, function and ligand binding. Curr Opin Microbiol 2007, 10(2):125-133.

58. Link TM, Valentin-Hansen P, Brennan RG: Structure of Escherichia coli Hfq bound to polyriboadenylate RNA. Proc Natl Acad Sci USA 2009, 106(46):19286-19291.

59. Beisel $\mathrm{CL}$, Updegrove $\mathrm{TB}$, Janson B, Storz G: Multiple factors dictate target selection by Hfq-binding small RNAs. EMBO J 2012, 31(8):1961-1974.

60. Schwarz KM, Kuit W, Grimmler C, Ehrenreich A, Kengen SWM: A transcriptional study of acidogenic chemostat cells of Clostridium acetobutylicum - Cellular behavior in adaptation to n-butanol. J Biotechnol 2012, 161(3):366-377.

61. Hou S, Jones SW, Choe LH, Papoutsakis ET, Lee KH: Workflow for quantitative proteomic analysis of Clostridia acetobutylicum ATCC 824 using iTRAQ tags. Methods 2013, 61(3):269-276.

10.1016/j.ymeth.2013.03.013.

62. Wang FQ, Kashket S, Kashket ER: Maintenance of Delta pH by a butanol-tolerant mutant of Clostridium beijerinckii. Microbiol-Sgm 2005 151:607-613.

63. Heipieper HJ, Weber FJ, Sikkema J, Keweloh H, Debont JAM: Mechanisms of Resistance of Whole Cells to Toxic Organic-Solvents. Trends Biotechnol 1994, 12(10):409-415.

64. Poritz MA, Bernstein HD, Strub K, Zopf D, Wilhelm H, Walter P: An Escherichia coli Ribonucleoprotein Containing 4.5s Rna Resembles Mammalian Signal Recognition Particle. Science 1990, 250(4984):1111-1117.

65. Honicke D, Janssen H, Grimmler C, Ehrenreich A, Lutke-Eversloh T: Global transcriptional changes of Clostridium acetobutylicum cultures with increased butanol:acetone ratios. N Biotechnol 2012, 29(4):485-493.

66. Cavanagh AT, Sperger JM, Wassarman KM: Regulation of 6S RNA by pRNA synthesis is required for efficient recovery from stationary phase in $\mathrm{E}$. coli and B. subtilis. Nucleic Acids Res 2012, 40(5):2234-2246.

67. Geissen R, Steuten B, Polen T, Wagner R: E. coli 6S RNA A universal transcriptional regulator within the centre of growth adaptation. RNA Biol 2010, 7(5):564-568.

68. Sharma UK, Chatterji D: Transcriptional switching in Escherichia coli during stress and starvation by modulation of Sigma 70 activity. FEMS Microbiol Rev 2010, 34(5):646-657.

69. Soutourina OA, Monot M, Boudry P, Saujet L, Pichon C, Sismeiro O, Semenova E, Severinov K, Le Bouguenec C, Coppée J-Y, et al: Genome-Wide Identification of Regulatory RNAs in the Human Pathogen Clostridium difficile. PLoS Genet 2013, 9(5):e1003493.

70. Chae H, Han K, Kim KS, Park H, Lee J, Lee Y: Rho-dependent Termination of ssrS (6S RNA) Transcription in Escherichia coli: implication for 3' processing of $6 \mathrm{~S}$ RNA and expression of downstream ygfA (putative 5-formyl-tetrahydrofolate cyclo-ligase). J Biol Chem 2011, 286(1):114-122.

71. Kim KS, Lee Y: Regulation of $6 \mathrm{~S}$ RNA biogenesis by switching utilization of both sigma factors and endoribonucleases. Nucleic Acids Res 2004, 32(20):6057-6068

72. Griffiths-Jones S, Moxon S, Marshall M, Khanna A, Eddy SR, Bateman A: Rfam: annotating non-coding RNAs in complete genomes. Nucleic Acids Res 2005, 33:D121-D124.

73. Faucher SP, Friedlander G, Livny J, Margalit H, Shuman HA: Legionella pneumophila 6S RNA optimizes intracellular multiplication. Proc Natl Acad Sci USA 2010, 107(16):7533-7538.

74. Keiler KC: Biology of trans-Translation. Annu Rev Microbio/ 2008 , 62:133-151

75. Tadaki T, Fukushima M, Ushida C, Himeno H, Muto A: Interaction of 10Sa RNA with ribosomes in Escherichia coli. FEBS Lett 1996, 399(3):223-226.

76. Felden B, Himeno H, Muto A, McCutcheon JP, Atkins JF, Gesteland RF: Probing the structure of the Escherichia coli 10Sa RNA (tmRNA). RNA 1997, 3(1):89-103.

77. Schönhuber W, Le Bourhis G, Tremblay J, Amann R, Kulakauskas S: Utilization of tmRNA sequences for bacterial identification. BMC Microbiol 2001, 1(1):20.

78. Barends S, Kraal B, van Wezel GP: The tmRNA-tagging mechanism and the control of gene expression: a review. Wires RNA 2011, 2(2):233-246.

79. Barends S, Zehl M, Bialek S, de Waal E, Traag BA, Willemse J, Jensen ON, Vijgenboom E, van Wezel GP: Transfer-messenger RNA controls the translation of cell-cycle and stress proteins in Streptomyces. EMBO Rep 2009, 11(2):119-125

80. Andre G, Even S, Putzer H, Burguiere P, Croux C, Danchin A, Martin-Verstraete I, Soutourina O: S-box and T-box riboswitches and antisense RNA control a sulfur metabolic operon of Clostridium acetobutylicum. Nucleic Acids Res 2008, 36(18):5955-5969.

81. Cornillot E, Nair RV, Papoutsakis ET, Soucaille P: The genes for butanol and acetone formation in Clostridium acetobutylicum ATCC 824 reside on a large plasmid whose loss leads to degeneration of the strain. J Bacteriol 1997, 179(17):5442-5447.

82. Nair RV, Bennett GN, Papoutsakis ET: Molecular characterization of an aldehyde/alcohol dehydrogenase gene from Clostridium acetobutylicum ATCC 824. J Bacteriol 1994, 176(3):871-885.

83. Harris LM, Welker NE, Papoutsakis ET: Northern, morphological, and fermentation analysis of spo0A inactivation and overexpression in Clostridium acetobutylicum ATCC 824. J Bacteriol 2002, 184(13):3586-3597. 
84. Fischer RJ, Helms J, Durre P: Cloning, sequencing, and molecular analysis of the Sol operon of Clostridium acetobutylicum, a chromosomal locus involved in solventogenesis. J Bacterio/ 1993, 175(21):6959-6969.

85. Nair RV, Green EM, Watson DE, Bennett GN, Papoutsakis ET: Regulation of the sol locus genes for butanol and acetone formation in Clostridium acetobutylicum ATCC 824 by a putative transcriptional repressor. J Bacteriol 1999, 181(1):319-330.

86. Harris LM, Blank L, Desai RP, Welker NE, Papoutsakis ET: Fermentation characterization and flux analysis of recombinant strains of Clostridium acetobutylicum with an inactivated solR gene. J Ind Microbiol Biotechnol 2001, 27(5):322-328.

87. Schiel $B$, Nold N, Dürre P: Identification of a small noncoding RNA in Clostridium acetobutylicum. Programme for the 3rd Joint Conference of the German Society for Hygiene and Microbiology (Jahrestagung der Deutschen Gesellschaft für Hygiene und Mikorobiologie [DGHM]) and the Association for General and Applied Microbiology (Jahrestagung der Vereinigung für Allgemeine und Angewandte Mikrobiologie [VAAM]), 28 to 31 March 2010. Hannover, Germany: GRV09:135; 2010.

88. Trapnell C, Pachter L, Salzberg SL: TopHat: discovering splice junctions with RNA-Seq. Bioinformatics 2009, 25(9):1105-1111.

89. Anders S, Huber W: Differential expression analysis for sequence count data. Genome Biol 2010, 11(10):R106.

90. Macke TJ, Ecker DJ, Gutell RR, Gautheret D, Case DA, Sampath R: RNAMotif, an RNA secondary structure definition and search algorithm. Nucleic Acids Res 2001, 29(22):4724-4735.

91. Lambert A, Fontaine JF, Legendre M, Leclerc F, Permal E, Major F, Putzer H, Delfour O, Michot B, Gautheret D: The ERPIN server: an interface to profile-based RNA motif identification. Nucleic Acids Res 2004 32:W160-W165

92. Gruber AR, Lorenz R, Bernhart SH, Neuboock R, Hofacker IL: The Vienna RNA Websuite. Nucleic Acids Res 2008, 36:W70-W74.

93. Hofacker IL: Vienna RNA secondary structure server. Nucleic Acids Res 2003, 31(13):3429-3431.

doi:10.1186/1471-2164-14-849

Cite this article as: Venkataramanan et al:: The Clostridium small RNome that responds to stress: the paradigm and importance of toxic metabolite stress in C. acetobutylicum. BMC Genomics 2013 14:849.

\section{Submit your next manuscript to BioMed Central and take full advantage of:}

- Convenient online submission

- Thorough peer review

- No space constraints or color figure charges

- Immediate publication on acceptance

- Inclusion in PubMed, CAS, Scopus and Google Scholar

- Research which is freely available for redistribution 